\title{
DETECTION OF MACROLIDE ASOCIATED MUTATIONS IN MYCOPLASMA GENITALIUM FROM CLINICAL SAMPLES IN ARGENTINA
}

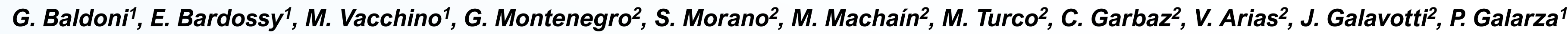

${ }_{1}$ National Reference Laboratory of Sexually Transmitted Diseases, National Institute of Infectious Diseases- ANLIS “Dr. Carlos G. Malbrán”, CABA, ARGENTINA

${ }^{2}$ National Laboratory Network of Sexually Transmitted Infections. ARGENTINA

Contact: pgalarza@anlis.gov.ar

\section{Background}

Mycoplasma genitalium $(\mathrm{Mg})$ is a sexually transmitted pathogen responsible for approximately $15 \%-20 \%$ of nongonococcal urethritis in male. In women several studies have shown an association between $M g$ and cervicitis, endometritis and pelvic inflammatory disease, although the association between infection and symptoms is weaker compared to men. In recent years, an increase in the $M g$ resistance to several antimicrobial agents used in treatments has been observed. Thus, it is speculated that $M g$ is evolving into what is commonly classified as superbug.

\section{Methods}

$27 \mathrm{Mg}$ positive samples recovered from genital sites submitted for diagnosis to the National Reference Laboratory for Sexual Transmitted Diseases between 2013-2017 were analyzed.

A DNA fragment of $147 \mathrm{bp}$ from region $\mathrm{V}$ of the $23 \mathrm{~S}$ rRNA was amplified and then sequenced searching for macrolide resistance associated mutations.

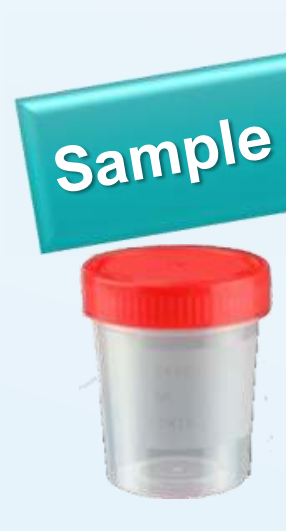

Clinical

sample
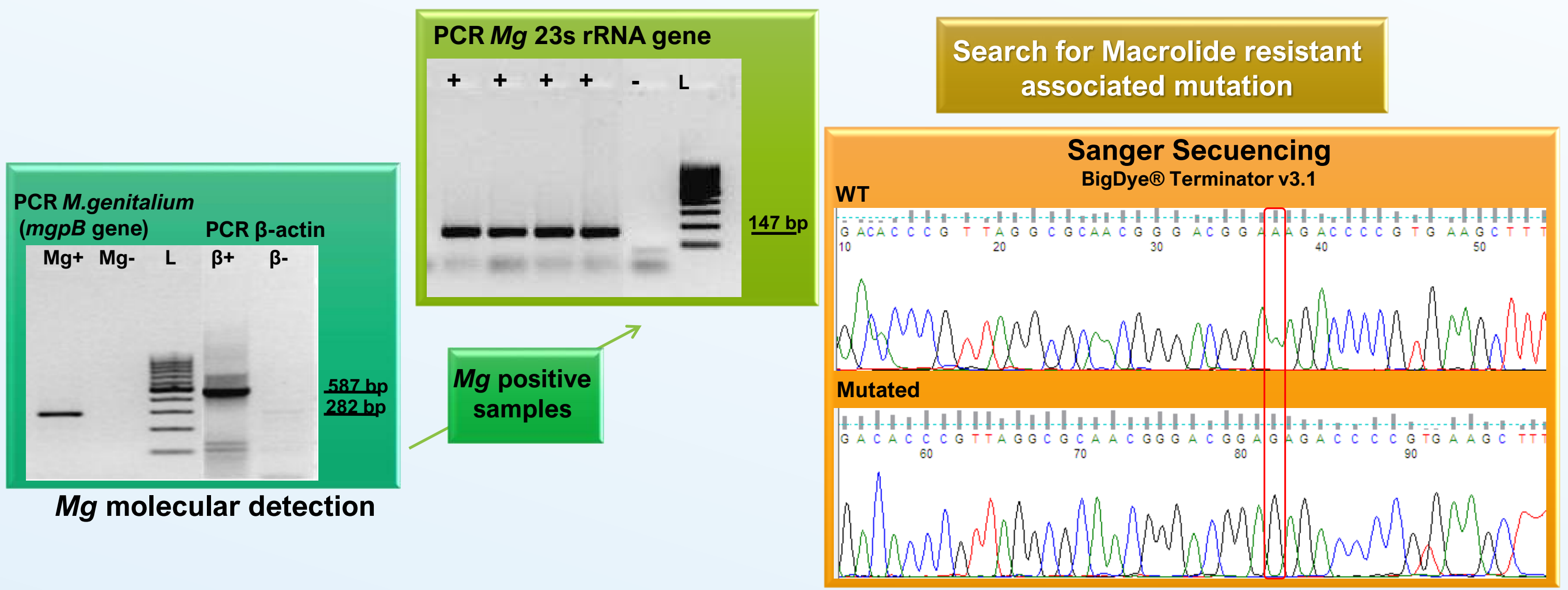

\section{Results}

27 different urogenital samples were analyzed (Fig. 1). Median age of patients was 25 years (a range 18 to 47 ). 19 patients were symptomatic at the time of sampling and 5 presented Chlamydia trachomatis co-infection (Fig. 2). Of the $27 \mathrm{Mg}$ positive only 22 could be sequenced in search for mutations.

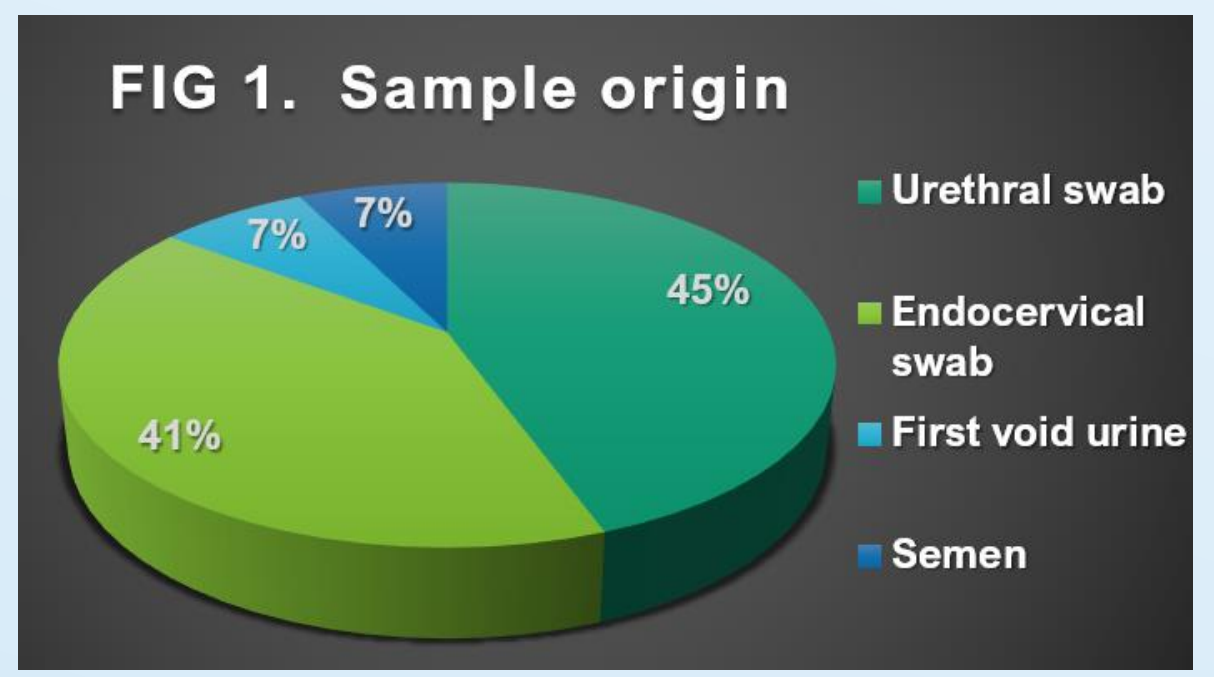

20 samples were wild type genotype at the positions 2058 and 2059 ( $E$. coli numbering) and 2 samples presented a A2059G transition previously associated with macrolide

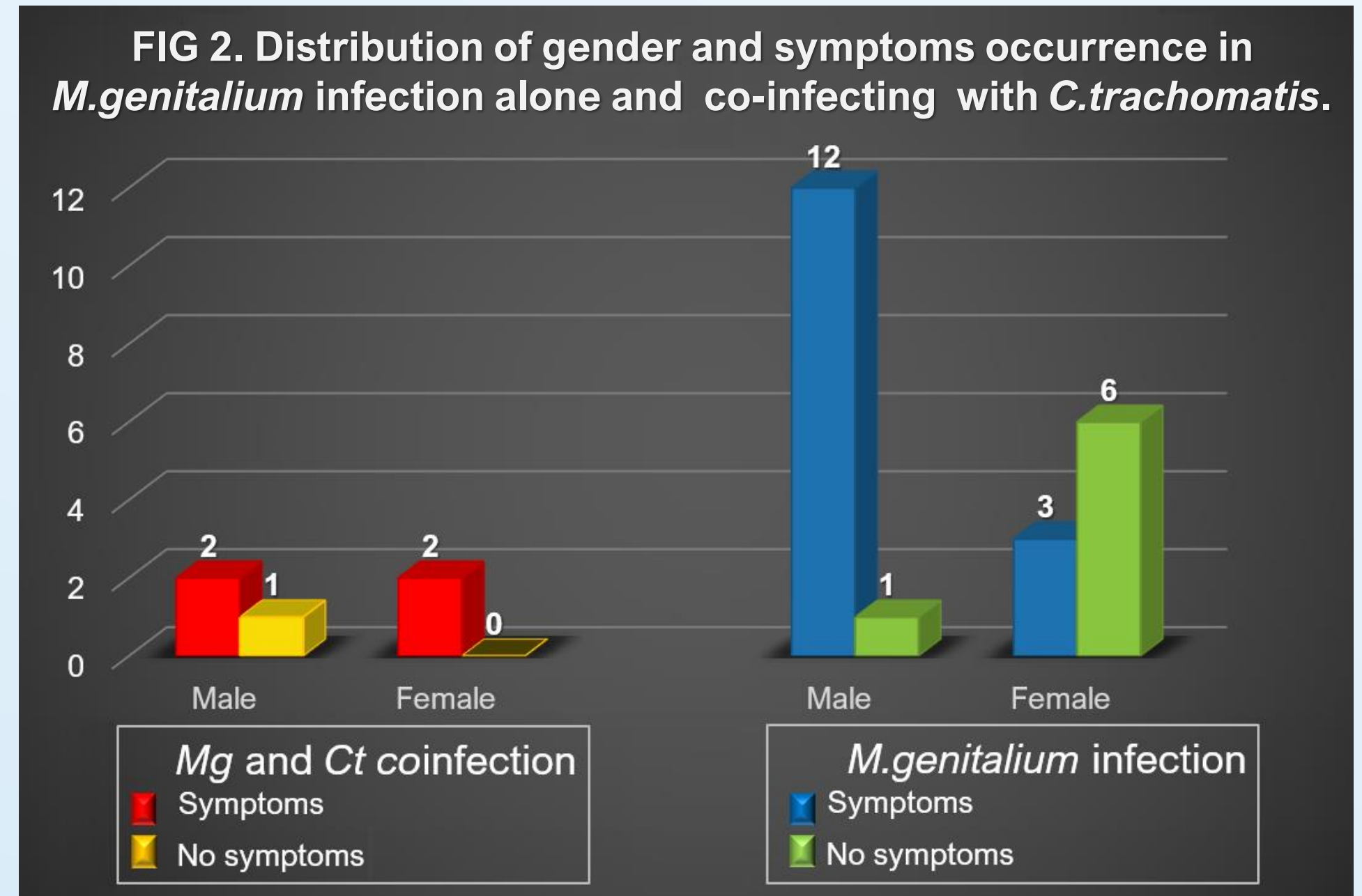
resistance (Fig. 3): "IMMy10098" came from an asymptomatic 22 years old male patient without previous treatment. "IMCt2235" from a 19 years old male patient, who had received treatment with macrolides, fluoroquinolone and $\beta$-lactams antibiotics. The last one also presented a missense mutation in the parC gene.

Fig 3. Sequence alignment of samples with Azithromycine resistance associated mutation.

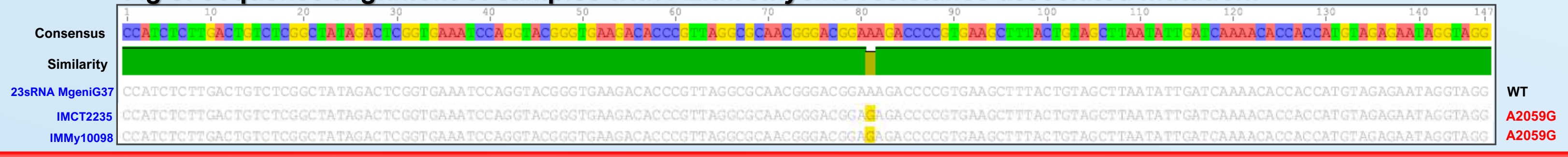

Conclusion

The detection of the described mutation in 2 out of 27 samples analyzed shows the presence of macrolide resistant $\mathrm{Mg}$ in our population. Considering the patients history, one of them could have develop intra treatment resistance, but the other one most likely could have been infected with an already resistant $\mathrm{Mg}$ strain. In either case, it is clear the necessity to perform further and thorough epidemiological studies and eventually initiate surveillance strategies in order to contribute with prevention and control of sexually transmitted infections in general, but also to establish proper and effective empirical therapy, stopping the spread of resistant strains. 